\title{
Attitude towards desire for implant treatment among outpatients of a Teaching Dental Hospital, Khammam
}

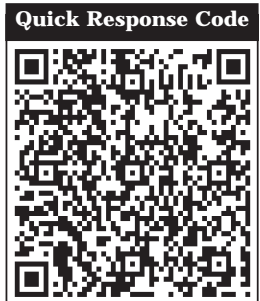

\section{doi: 10.5866/2015.7.10022}

${ }^{1}$ Post Graduate Student

2Professor and HOD

${ }^{3}$ Professor

${ }^{4}$ Reader

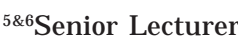

Department of Public Health Dentistry,

Mamata Dental College,

Khammam, Telangana State, India

\section{Article Info:}

Received: J anuary 12, 2015

Review Completed: February 10, 2015

Accepted: March 11, 2015

Available Online: April, 2015 (www.nacd.in)

(c) NAD, 2015 - All rights reserved

\section{Email for correspondence:}

venkataramana528@gmail.com
Venkata Ramana $\mathrm{M}^{1}$, Pratap KVNR ${ }^{2}$, Madhavi Padma $\mathrm{T}^{3}$, Siva Kalyan $V^{4}$, Bhargava ASK ${ }^{5}$, Surya Chandra Varma $L^{6}$

\section{INTRODUCTION}

The main role of prosthodontics is the rehabilitation of patients after loss of teeth and oral function. ${ }^{1}$ Common oral conditions have been shown to have a substantial effect on well-being and quality of life. The research in dentistry resulted in many

\begin{abstract}
:
Background: The main goal of research in modern dentistry is to restore the patient to normal function, aesthetics and speech. Research in dentistry resulted in many rehabilitation procedures. Despite of new available restorative options it is observed that there are substantial barriers between need and demand and demand and utilization. This is possibly due to lack of information and awareness and poor financial status.
\end{abstract}

Aim: The purpose of this survey is to evaluate awareness, interest and obstructions towards implant treatment among outpatients of the teaching Dental hospital, Khammam.

Materials and method: A self-explanatory closed type of questionnaire which evaluates patient's awareness, interest and barriers to obtain an implant treatment was given to a sample of 300 outpatients of teaching Dental Hospital.

Results: Out of 310 participants, 300 responded to the questionnaire with a response rate of $96.77 \%$. Among them 232 (77.33\%) subjects were males and $68(22.67 \%)$ were females. $98.6 \%$ of sample feels replacement of lost tooth is necessary of which $275(91.67 \%)$ says it is for performing masticatory functions and $23(7.67 \%)$ says for aesthetics. Misconceptions about implant treatment are about 93 (31\%). In the sample 169 (56.33\%) feels it is an expensive though willing cannot afford. Long duration of treatment plan and fear about surgery among $117(39 \%)$ and $123(41 \%)$ respectively are barriers to success of implant procedure.

Conclusion: The results of the survey reveal lower awareness towards implant treatment and socioeconomic status of the population making difficult to reach a common man.

Key words: Awareness, Dental implant, Attitude, Edentulous.

\section{Indian Journal of Dental AdVANCEMEnTS}

Journal homepage: www. nacd. in 
prosthesis at all.1,3 This may be because of various factors involving anatomy, physiology, psychology and Prosthodontics. Inferior masticatory ability, difficulty with denture retention, speech and mastication makes removable prosthesis difficult to accept.

With advent of new technol ogy more restorative options have become available thereby changing the face of demand for Prosthodontics treatment. Among them implant treatment has come into focus since it provides excellent long term results in rehabilitation. The unique feature of implant is able to achieveideal goal regardless of atrophy and injury to stomatognathic system ${ }^{4}$ Dental implants have proven to be having a high efficacy rate which is evident from several long term clinical trials. ${ }^{5}$

Reports from Finland, Australia, Austria have shown that the level of awareness of dental implant treatment procedure in selected group of samples is $29 \%, 64 \%, 72 \%$ respectively. ${ }^{6}$ A wareness among people about treatment procedure like implant is the major criteria in devel oping countries like I ndia. ${ }^{4}$ Similarly, incomplete information, negative information, treatment cost, fear of surgery, long post surgical period, false believes among public are barriers to take implant treatment procedure in country. Thus the present study was conducted with an objective to determine awareness of implant supported prosthesis as a new modality to determine attitude of people towards implant treatment and to determine constraints in implant treatment like age, finance, fear of surgery etc.

\section{MATERIALS AND METHODS}

A descriptive cross sectional study was conducted on patients attending outpatient ward of the teaching Dental Hospital, Khammam. A total of 310 were approached of them 300 were agreed to participate questionnaire with a response rate of $96.77 \%$. Patients willing to participate and between the age group of 20 to 65 years were taken into the study. Ethical clearance was obtained from the ethical committee of Dental College, Khammam.

Study instrument has two parts in which demographic data like patient age and gender are recorded in the first part. The other part included a close ended questionnaire with 11 questions. Validity of questionnaire was ensured by panel of experts in the field, framing was done as per their suggestion. A pilot study was doneto assess changes in the terminology.
The results were analyzed by using SPSS18 software. Descriptive statistics were generated to summarize the response. Analysis of gender was done using chi square test.

\section{RESULTS}

The subjects were categorized based on gender and age group. The subjects were between 21 years to 60 years of age of which $77.33 \%$ male (232) and $22.67 \%$ female (68). The maximum numbers of respondents were between $21-30$ years of age which indicates literacy rate to maximum. The age group between $51-60$ years constitutes a minimum of $15 \%$ of the sample.Among the partici pants who answered the questionnaire $42.3 \%$ were of $21-30$ years age group, $23.3 \%$ between $31-40,19.33 \%$ between $41-50$ and $15 \%$ between $51-60$ years (Table 1 ). The mean age that have participated in study is 36.67 for male and 35.24 for female (Table 2).

$98.6 \%$ of sample feels replacement of lost tooth is necessary. Majority (91.67\%) says it is for performing functions and 23 (7.67\%) for aesthetics. $188(62.67 \%)$ of sample know about both removable and fixed type of prosthetic treatment. Only 78 (29.33\%) are aware of implant treatment procedure. Misconceptions about implant treatment among the sample are about 93 (31\%). In the sample majority 169 (56.33\%) feels it is an expensive though willing cannot afford. 117 (39\%) of them felt that the long duration in treatment plan is one of the drawback for treatment procedure. Fear about surgery 123 $(41 \%)$ are barriers in success of implant procedure. Only $3 \%$ of the studied sample has undergone this procedure (Table 3).

Almost equal proportion of male and female in the sample responded positively about need for replacement, awareness about removable and fixed prosthesis. Fear towards surgery is more among female $(57 \%)$ than that of $(40 \%)$ of sample in male population and the difference was statistically significant $(p=0.0270)$. Statistically significant difference was found between males and females with regards to age at which people can undergo implants treatment, and cost of treatment. $(p=0.0000, p=0.3000)$ (Table 4).

\section{DISCUSSION:}

Dental implant treatment has become the first choice of treatment procedure for replacing missing tooth. The uniquefeatures of implant made it widely 
Table 1: Distribution of study samples by age groups and gender

\begin{tabular}{lrrrrrrr}
$\begin{array}{l}\text { Age } \\
\text { groups }\end{array}$ & Male & \multicolumn{2}{c}{$\%$ Female } & $\%$ & Total & $\%$ \\
21-30yrs & 100 & 78.74 & 27 & 21.26 & 127 & 42.33 \\
\hline $31-40 y r s$ & 49 & 70.00 & 21 & 30.00 & 70 & 23.33 \\
\hline $41-50 y r s$ & 46 & 79.31 & 12 & 20.69 & 58 & 19.33 \\
\hline $51-60 y r s$ & 37 & 82.22 & 8 & 17.78 & 45 & 15.00 \\
\hline Total & 232 & 77.33 & 68 & 22.67 & 300 & 100.00 \\
\hline
\end{tabular}

Table 3: Item wise responses

Items No of respondents \% of respondents Q1

\begin{tabular}{lcc}
\hline No & 4 & 1.33 \\
\hline Yes & 296 & 98.67 \\
\hline Q2. & & \\
\hline Beauty & 23 & 7.67 \\
\hline Function & 275 & 91.67 \\
\hline Other & 2 & 0.67
\end{tabular}

Q3.

\begin{tabular}{lcc}
\hline No & 112 & 37.33 \\
\hline Yes & 188 & 62.67 \\
\hline Q4. & 182 & 70.67 \\
\hline No & 118 & 29.33 \\
\hline Yes & & \\
\hline Q5. & 207 & 69.00 \\
\hline No & 93 & 31.00 \\
\hline Yes & & \\
\hline Q6. & 131 & 43.67 \\
\hline No & 169 & 56.33 \\
\hline Yes & 113 & \\
\hline Q7. & 147 & 41.00 \\
\hline No & & 49.00 \\
\hline Yes & 177 & \\
\hline Q8. & 123 & 49.00 \\
\hline No & & 41.00 \\
\hline Yes & 183 & 61.00 \\
\hline Q9. & 117 & 39.00 \\
\hline No & & \\
\hline Yes & 115 & 36.67 \\
\hline Q10. & 145 & 63.33 \\
\hline No & & \\
\hline Yes & 291 & 3.00 \\
\hline Q11. & 900 & \\
\hline No & & \\
\hline Yes & & \\
\hline Total & & \\
\hline *p 0.05 & & \\
\hline
\end{tabular}

$* \mathrm{p}<0.05$
Table 2: Mean and SD age by gender Male Female Total

$\begin{array}{llll}\text { Mean age } & 36.67 & 35.24 & 36.34\end{array}$
\begin{tabular}{llll}
\hline SD age & 11.14 & 11.31 & 11.18
\end{tabular}

Table 4: Comparison of male and females with respect to each question

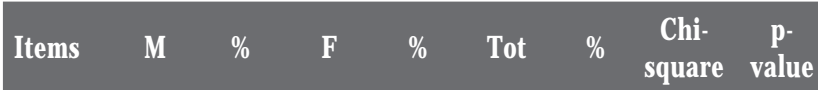

Q1

\begin{tabular}{lcccccccc}
\hline No & 3 & 75.00 & 1 & 25.00 & 4 & 1.33 & 0.0126 & 0.9107 \\
\hline Yes & 229 & 77.36 & 67 & 22.64 & 296 & 98.67 & &
\end{tabular}

Q2

$\begin{array}{lllllllll}\text { Beauty } & 17 & 73.91 & 6 & 26.09 & 23 & 7.67 & 0.7420 & 0.6900\end{array}$

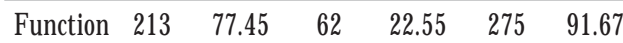

\begin{tabular}{lllllll}
\hline Other & 2 & 100.00 & 0 & 0.00 & 2 & 0.67
\end{tabular}

Q3

\begin{tabular}{lllllllll} 
No & 82 & 73.21 & 30 & 26.79 & 112 & 37.33 & 1.7299 & 0.1884 \\
\hline
\end{tabular}

\begin{tabular}{lllllll}
\hline Yes & 150 & 79.79 & 38 & 20.21 & 188 & 62.67
\end{tabular}

Q4

$\begin{array}{lllllllll}\text { No } & 114 & 75.00 & 38 & 25.00 & 152 & 50.67 & 0.9570 & 0.3280\end{array}$

$\begin{array}{lllllll}\text { Yes } & 118 & 79.73 & 30 & 20.27 & 148 & 49.33\end{array}$

Q5

$\begin{array}{lllllllll}\text { No } & 167 & 80.68 & 40 & 19.32 & 207 & 69.00 & 4.2572 & 0.0391^{*}\end{array}$

\begin{tabular}{llllllll}
\hline Yes & 65 & 69.89 & 28 & 30.11 & 93 & 31.00
\end{tabular}

Q6

\begin{tabular}{lllllllll}
\hline No & 100 & 76.34 & 31 & 23.66 & 131 & 43.67 & 0.1320 & 0.7164 \\
\hline
\end{tabular}

$\begin{array}{lllllll}\text { Yes } & 132 & 78.11 & 37 & 21.89 & 169 & 56.33\end{array}$

Q7

$\begin{array}{lllllllll}\text { No } & 101 & 66.01 & 52 & 33.99 & 153 & 51.00 & 22.8273 & 0.0000^{*}\end{array}$

$\begin{array}{lllllll}\text { Yes } & 131 & 89.12 & 16 & 10.88 & 147 & 49.00\end{array}$

Q8

\begin{tabular}{lllllllll}
\hline No & 129 & 72.88 & 48 & 27.12 & 177 & 59.00 & 4.8814 & $0.0272^{*}$
\end{tabular}

\begin{tabular}{lllllll}
\hline Yes & 103 & 83.74 & 20 & 16.26 & 123 & 41.00
\end{tabular}

Q9

$\begin{array}{lllllllll}\text { No } & 139 & 75.96 & 44 & 24.04 & 183 & 61.00 & 0.5076 & 0.4762\end{array}$

\begin{tabular}{lllllll}
\hline Yes & 93 & 79.49 & 24 & 20.51 & 117 & 39.00
\end{tabular}

Q10

\begin{tabular}{lllllllll}
\hline No & 112 & 72.26 & 43 & 27.74 & 155 & 51.67 & 4.7125 & $0.0300^{*}$ \\
\hline
\end{tabular}

\begin{tabular}{lllllll}
\hline Yes & 120 & 82.76 & 25 & 17.24 & 145 & 48.33
\end{tabular}

Q11

\begin{tabular}{lllllllll}
\hline No & 226 & 77.66 & 65 & 22.34 & 291 & 97.00 & 0.6022 & 0.4377
\end{tabular}

\begin{tabular}{lllllll}
\hline Yes & 6 & 66.67 & 3 & 33.33 & 9 & 3.00
\end{tabular}

$\begin{array}{lllllll}\text { Total } & 232 & 77.33 & 68 & 22.67 & 300 & 100.0\end{array}$

${ }^{*} p<0.05$ 
accepted. The comfort and confidence given by a fixed prosthesis can never be compared to any ideal removable appliance. In spite of its benefits the wide acceptance of the implant treatment procedure becomes challenged in developing countries like India. Hence to evaluate a survey was conducted to know the patients' attitude to undergo implant treatment.

Around one million dental implants are inserted each year, worldwide. ${ }^{7}$ However, information which is available to the patients regarding the procedure and its success, is often fragmentary. This problem is more compounded in developing nations. In the present study, awareness regarding implants were among $29.33 \%$ participants which was very less than other studies done by Zimmer et al (1992), Berge (2000) and Tepper et al (2003) which reported the level of awareness as 77, 70.1 and $72 \%$, respectively. 5, 8,9 It could be due to low level of education in the study sample as most of the people belong to rural community. But the results of the present study were higher than Chowdhary $\mathrm{R}$ et al among Indian population in 2010. ${ }^{3}$

When questions were asked regarding constraints of implants, most of them mentioned high cost as the major factor. Some patients think that, the implant is a major surgical procedure because of the use of the word surgery. Similar results are obtained in most of the previously mentioned studies: Kaurani P et al (2010), J ohany SA et al (2010), Tepper et al (2003), Kent (1992) and Zimmer et al (1992).5, 6, 9-11

The analyzed sample gave different results in male and female population. The poorer social awareness in female made less knowledge about implant treatment. The misconceptions and fear about surgery are more among the female sample. Male population accepted cost procedure and showed willingness with its long term results. Long duration of procedure is a disadvantage in the treatment was expressed by the male population. Statistically significant difference was found between males and females with regards to age at which people can undergo implants treatment, fear of surgery for implant placement and cost of treatment.

These barriers are to be removed by increasing awareness among the subjects. Population often showed interest to know about treatment during the study.

\section{CONCLUSION}

Interest to know new treatment modalities is high among the population. Providing proper information makes some population aware about the treatment and allow other population with misconceptions to correct them. Dentists, media, arts play an important role in this. Providing financial support also increase the proportion of implant under taking the sample.

\section{REFERENCES:}

1. Suprakash B, Ahammed ARY, Thareja A, Kandaswamy R, Kumar N, Bhondwe S. Knowledge and Attitude of Patients toward Dental Implants as an Option for Replacement of Missing Teeth. J Contemp Dent Pract 2013; 14(1):115-118.

2. Bhat AM, Prasad KD, Sharma D, Hegde R. Attitude toward Desire for I mplant Treatment in South Coastal Karnataka Population: A Short-term E pidemiological Survey. Int J Oral ImplantolClin Res 2012; 3(2):63-66.

3. Chowdhary R, Mankani N, Chandrakar NK. Awareness of dental implant as a treatment choice in urban Indian population. Int J oral maxillofac implants 2010; 25:305-308.

4. Ravikumar C, Pratap KVNR, Venkateswararao G. Dental implants as an option in replacing missing teeth: a patient awareness survey in khammam, Andhrapradesh. IJ DS 2011; 5(3):33-37.

5. Zimmer CM, Zimmer WM, Williams J, Liesener J . Public awareness and acceptance of dental implants. Int J Oral Maxillo-fac I mplants 1992; 7(2):228-232.

6. Sulieman Al J ohany, Hamad A Al Zoman, Mohannad Al J uhaini. Dental patients awareness and knowledge in using dental implants as an option in replacing missing teeth: A survey in Riyadh, Saudi Arabia. The Saudi dental journal 2010; 22:183-188.

7. Pragati K, Mayank K. Awareness of dental implants as a treatment modality amongst people residing in J aipur (Rajasthan). J Clin Diagn Res 2010; 4:3622-3626.

8. Berge TI. Public awareness, information sources and evaluationof oral implant treatment in Norway. Clin Oral Implants Res 2000; 11(5):401-408.

9. Tepper G, Haas R, Mailath G, Teller C, Zechner W, Watzak $G$, et al. Representative marketing-oriented study on implants inthe Austrian population. I. Level of information, sources ofinformation and need for patient information. Clin Oral I mplants Res 2003; 14(5):621-633.

10. Kaurani P, Kaurani M. Awareness of dental implants as atreatment modality amongst people residing in J aipur (Rajasthan). J Clin Diagn Res 2010; 4:3622-3626

11. Kent G. Effects of osseointegrated implants on psychologicaland social well-being: A literature review. J Prosthet Dent 1992; 68(3):515-518. 